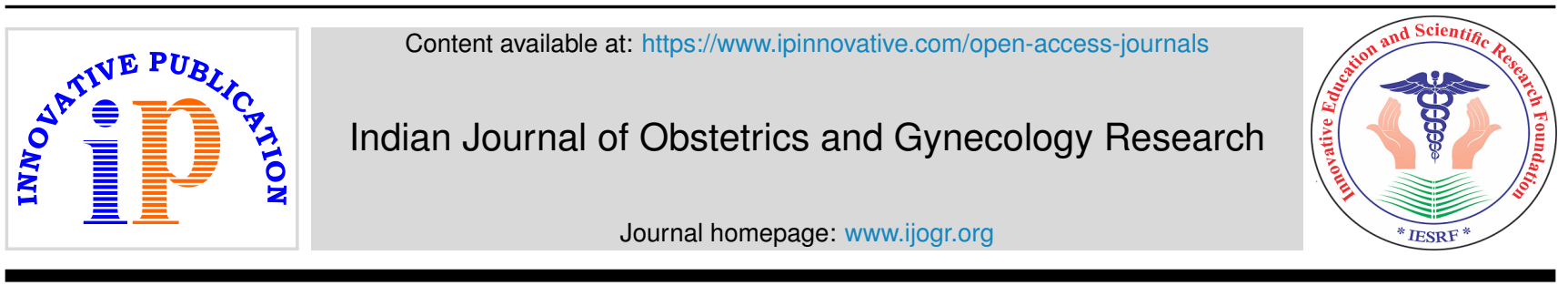

Original Research Article

\title{
A comparative study of efficacy of DIPSI and O'Sullivan's method of screening for GDM in a high risk tertiary referral hospital
}

\author{
Rashmi K ${ }^{1}$, Tejaswini $D^{1}$, Radhika ${ }^{1}$, Anitha G $S^{1, *}$, Sukanya $S^{1}$ \\ ${ }^{1}$ Dept. of Obstetrics and Gynaecology, Vanivilas Hospital, Bangalore Medical College \& Research Institute, Bangalore, \\ Karnataka, India
}

\section{A R T I C L E I N F O}

\section{Article history:}

Received 17-05-2020

Accepted 24-12-2020

Available online 13-03-2021

\section{Keywords:}

Gestational diabetes mellitus

DIPSI

Blood glucose

\begin{abstract}
A B S T R A C T
Introduction: There is an increasing trend of making Diabetes one of the most common noncommunicable diseases globally. Gestational Diabetes Mellitus (GDM) is defined as "carbohydrate intolerance variable severity that is first diagnosed during present pregnancy, regardless of the need for insulin or persistence of the diabetic state after delivery". Diabetes Mellitus is the most common disorder of pregnancy, although the prevalence is usually reported as 2 to $5 \%$ of pregnant women, it can be as high as $14 \%$ in high risk groups.

Aims and Objective: To note the Foetal Outcome of pregnancy with impaired and abnormal glucose tolerance detected with DIPSI.

Materials and Methods: Total of 200 patients was included in the study from Vanivilas hospital for 1 year. A detailed history from antenatal patients was taken to reveal all risk factors. The procedure of the study was explained and required consent for the study was taken. Examination of the patients was done and all relevant data was obtained. Fasting blood glucose was taken of all antenatal patients at their first visit. Pregnant women at 24-28 weeks were tested with $50 \mathrm{~g}$ oral glucose load or $75 \mathrm{~g}$ oral glucose load, at random. Patients were give $50 \mathrm{~g}$ glucose irrespective of the meal and 1 hour venous blood sample was collected. Patients of $75 \mathrm{~g}$ of oral glucose were asked to come in fasting state, $75 \mathrm{~g}$ of glucose was given, and following which 2 hour venous sample was collected. Blood glucose was tested by GOD-POD method. Diagnosis of GDM was made when the plasma glucose of $>140 \mathrm{mg} / \mathrm{dL}$ and impaired glucose tolerance diagnosis was made when plasma glucose was between $120-140 \mathrm{mg} / \mathrm{dl}$.

Conclusion: High prevalence rate of GDM was obtained in our study, GDM has adverse maternal and fetal outcome. GDM when identification early and treatment initiated for mothers, maternal and fetal complications can be reduced. In conclusion, intensive care of GDM mothers can help primary prevention of obesity, impaired glucose tolerance and diabetes in the offspring.
\end{abstract}

(C) This is an open access article distributed under the terms of the Creative Commons Attribution License (https://creativecommons.org/licenses/by/4.0/) which permits unrestricted use, distribution, and reproduction in any medium, provided the original author and source are credited.

\section{Introduction}

There is an increasing trend of making Diabetes one of the most common non-communicable diseases globally. Gestational Diabetes Mellitus (GDM) is defined as "carbohydrate intolerance variable severity that is first diagnosed during present pregnancy, regardless of the need for insulin or persistence of the diabetic state after delivery". 1,2 Diabetes Mellitus is the most common disorder

\footnotetext{
* Corresponding author.

E-mail address: aninaik85@gmail.com (Anitha G S).
}

of pregnancy, although the prevalence is usually reported as 2 to $5 \%$ of pregnant women it can be as high as $14 \%$ in high risk groups. ${ }^{1,2}$ The earlier studies by Langer et al $(1989)^{3}$ and Vambergue et al $(2000)^{4}$ reported that even mild gestational hyperglycaemia, if untreated, is associated with higher incidence of large infants and other metabolic complications occurring in patients with frank gestational diabetes. Women with GDM are also more likely to undergo caesarean section and to develop diabetes later in life. ${ }^{5}$ It has also been reported that between $35 \%$ and 
$50 \%$ of women with GDM will go on to develop type 2 diabetes within 5 years of giving birth. ${ }^{6,7}$ When the implications of untreated GDM are considered, including the peripartum risks (of macrosomia, hyperbilirubinemia, operative delivery, shoulder dystocia and birth trauma) the higher incidence of childhood obesity and longer term risk of type 2 diabetes in mother and offspring, a strong case can be made for effective screening and diagnostic tests in Indian population. The Fifth International Conference on GDM recommended grouping of pregnant women based on risk factors and two steps or one step testing for diagnosis of GDM.

\section{Aims and Objective}

1. To access the risk factors in pregnant women with GDM.

2. To note the perinatal outcome of pregnancy with impaired and abnormal glucose tolerance detected with DIPSI.

\section{Materials and Methods}

Total of 200 patients were included in the study from Vanivilas hospital for 1 year. A detailed history from antenatal patients was taken to reveal all risk factors. The procedure of the study was explained and required consent for the study was taken. Examination of the patients was done and all relevant data was obtained. Pregnant women at 24-28 weeks were tested with $50 \mathrm{~g}$ oral glucose load or $75 \mathrm{~g}$ oral glucose load, at random. Patients were given $50 \mathrm{~g}$ glucose irrespective of the meal and 1 hour venous blood sample was collected. Patients of $75 \mathrm{~g}$ of oral glucose were asked to come irrespective of the meal, $75 \mathrm{~g}$ of glucose was given, and following which 2 hour venous sample was collected. Blood glucose was tested by GOD-POD method. Diagnosis of GDM was made when the plasma glucose of $>140 \mathrm{mg} / \mathrm{dL}$ and impaired glucose tolerance diagnosis was made when plasma glucose was between $120-140 \mathrm{mg} / \mathrm{dl}$. Results were tabulated and analysed.

\section{Results}

Table 1: Age distribution

\begin{tabular}{lc}
\hline $18-20$ years & $42(21 \%)$ \\
$21-25$ years & $94(46 \%)$ \\
$25-30$ years & $55(27.5 \%)$ \\
$>30$ years & $9(4.5 \%)$
\end{tabular}

Majority of patients were found in the age group of 2125 years. 25-30 years age group had 55 patients. Least was seen in the age group above 30 years.

$61 \%$ of patients were multiparous. $39 \%$ of patients were primigravida
Table 2: Parity

\begin{tabular}{lc} 
Multiparous & $122(61 \%)$ \\
Primigravida & $78(39 \%)$ \\
\hline
\end{tabular}

Table 3: Socio economic status

\begin{tabular}{lc}
\hline Upper & $10(5 \%)$ \\
Middle & $102(51 \%)$ \\
Lower & $88(44 \%)$ \\
\hline
\end{tabular}

Most of our patients belonged to the middle socioeconomic status. $44 \%$ of patients were in the lower socioeconomic status. Only $5 \%$ of patients were in upper socioeconomic status.

Table 4: Body mass index

\begin{tabular}{lc}
18.5 (underweight) & $19 \mathrm{pts}(9.5 \%)$ \\
$18.5-24.9$ (normal weight) & $33 \mathrm{pts}(16.5 \%)$ \\
$25-29.9$ (over weight) & $84 \mathrm{pts}(42 \%)$ \\
$30-39.9$ (obesity) & $64 \mathrm{pts}(32 \%)$ \\
$>40$ (morbid obesity) & NIL \\
\hline
\end{tabular}

Patients with overweight contributed to the maximum(42\%) in our study. Next common group was obesity. $16.5 \%$ patients were of normal weight. $9.5 \%$ were underweight.

Table 5: Risk factors of present pregnancy

$\begin{array}{lc}\text { Hypothyroidism } & \text { No of Patients } \\ \text { HDP } & 29(14.5 \%) \\ \text { Known auto immune diseases } & 17(8.5 \%) \\ \text { placenta previa } & 0 \\ \text { FGR } & 3(1.5 \%) \\ \text { Fetal anomalies } & 14(7 \%) \\ \text { Abruption(33wks) } & 5(2.5 \%) \\ \end{array}$

Most common co-morbidity developed in by patients was hypothyroidism, next common being HDP. FGR was seen in 14 patients. Least common was placenta previa, abruption and fetal anomalies. No patients had any known auto immune diseases.

Table 6: Family history of diabetes melltus

\begin{tabular}{lc}
\hline Present & $115(57.5 \%)$ \\
Absent & $85(42.5 \%)$ \\
\hline
\end{tabular}

Most of our patients had family history of diabetes mellitus- up to $57.5 \%$. The rest had no family history of diabetes mellitus- up to $42.4 \%$

$13.5 \%$ of patients had previous history of GDM, $18 \%$ had macrosomia and $8 \%$ had IUFD.

Normal test results were obtained in $60 \%$ of patients. $18.5 \%$ had impaired results. $21.5 \%$ had GDM. 
Table 7: Previous history

\begin{tabular}{lc}
\hline GDM & $27(13.5 \%)$ \\
Macrosomia & $36(18 \%)$ \\
IUFD & $16(8 \%)$ \\
\hline
\end{tabular}

Table 8: Dipsi test results

\begin{tabular}{ll}
\hline Normal & $120(60 \%)$ \\
Impaired & $37(18.5 \%)$ \\
GDM & $43(21.5 \%)$
\end{tabular}

Table 9: Mode of delivery

\begin{tabular}{lc}
\hline Vaginal & $99(49.5 \%)$ \\
Instrumental & $14(7 \%)$ \\
LSCS & $87(43.5 \%)$ \\
\hline
\end{tabular}

$49.5 \%$ of patients delivered vaginally, $7 \%$ had instrumental delivery and $43.5 \%$ underwent LSCS.

Table 10: Period of gestation

\begin{tabular}{lc}
\hline Preterm & $7(3.5 \%)$ \\
Term $(>=37$ weeks $)$ & $193(96.5 \%)$ \\
\hline
\end{tabular}

$3.5 \%$ of patients had preterm delivery and the rest had term delivery. Causes of preterm delivery were severe preeclampsia ( 2 cases), APH ( 1 case), FGR (4 cases).

Table 11: Birth weight of babies

\begin{tabular}{lc}
\hline$<1.5 \mathrm{~kg}$ & $1(0.5 \%)$ \\
$1.5-2.5 \mathrm{~kg}$ & $30(15 \%)$ \\
$2.5-3.5 \mathrm{~kg}$ & $146(73 \%)$ \\
$>3.5 \mathrm{~kg}$ & $23(12.5 \%)$ \\
\hline
\end{tabular}

$73 \%$ of babies had normal birth weight, $11.5 \%$ were greater than $3.5 \mathrm{~kg}, 15 \%$ had birth weight of $1.5-2.5 \mathrm{~kg}$ and 1 baby weighed less than $1.5 \mathrm{~kg}$.

Table 12: Complications in neonates

\begin{tabular}{lc}
\hline Complications & \\
No complications & $152(76 \%)$ \\
Macrosomia & $11(5.5 \%)$ \\
Still birth & $2(1 \%)$ \\
Shoulder dystocia & $1(0.5 \%)$ \\
Neonatal Hypoglycaemia & $29(14.5 \%)$ \\
Trauma/Injury & 0 \\
Congenital abnormality & $5(2.5 \%)$ \\
\hline
\end{tabular}

Few babies had neonatal complications like macrosomia (5.5\%), neonatal hypoglycaemia (14.5\%), congenital anomalies $(2.5 \%)$. There were $2(1 \%)$ still births and $1 \%$ had shoulder dystocia.

There were no trauma/ injury to neonates. $76 \%$ babies were normal.

\section{Discussion}

A total of 200 antenatal patients were studied. The present study aim was to identify cases of gestational diabetes mellitus and to study their fetal outcomes. GDM prevalence varies from 1.4 to $14 \%$ worldwide and varies with racial and ethnic groups. In our study, GDM comprises of $21.5 \%$ of the total screened patients. Majority of the patients were from middle socio economic status. In a study in Maharashtra the prevalence of carbohydrate intolerance was found to be 7.7 percent. ${ }^{8}$ In our study, maximum patients $(47 \%)$ were in the age group of 21-25 years and $27.5 \%$ of patients were between 25-30 years of age. A study in Kashmir stated that compared with women of normal OGTT, women with GDM were older. ${ }^{9}$ According to the pathophysiology of the disease, GDM affects older women more than younger ones. It is also known that cardiovascular risk factors may be present in older women and hence primary prevention in these patients would be extremely important to prevent future cardiovascular disease. In the present study, $39 \%$ patients were primigravida while $61 \%$ patients were multigravida. The study by Rajput et al., showed that higher parity would have a higher rate of GDM. ${ }^{10}$ Positive family history as a risk factor was noted in $57.7 \%$, in our study. In the study conducted in united kingdom by Nanda et al, positive family history was found in $23.9 \%$ patients. ${ }^{11}$ Pre-eclampsia can complicate the course of pregnancy and has an adverse effect on the feto-maternal outcome. In this study $8.5 \%$ of GDM patients had associated HDP. In the study be Saxena et al., the incidence of pre-eclampsia was 40\%. ${ }^{12}$ According to Xiong et al., mothers with GDM were at increased risk of presenting with pre-eclampsia. ${ }^{13}$ Thus there is an association between pre-eclampsia and GDM and early diagnosis and initiation of treatment should be done to improve the outcome. Hypothyroidism was noted in $14.5 \%$ of patients in the present study. ${ }^{14}$

$49.5 \%$ patients in this study delivered vaginally. $7 \%$ deliveries were instrumental assisted delivery. In this study $43.5 \%$ patients underwent LSCS. According to Kale et al, the incidence of LSCS in patients with GDM was found to be $60 \% .{ }^{15}$ In the present study, $96.5 \%$ of babies were born at term and $3.5 \%$ were pre-term. In a study by Mahalakshmi $\mathrm{MM}$ et al., in South India, $77.5 \%$ of babies were term live births while $19 \%$ were preterm live birth. ${ }^{16}$ Preterm births in present study were attributed to Causes of preterm delivery were severe preeclampsia ( 2 cases), APH (1 case), FGR (4 cases). The Indian consensus is that a new born weighing $>3.5 \mathrm{~kg}$ should be considered as macrosomia. In present study, $11.5 \%$ babies were macrosomic at birth which is low compared to other Indian studies where the incidence (weight $<2.5 \mathrm{~kg}$ ) was $20 \%$.

Common Complications noted in neonates born to GDM mothers include fetal macrosomia, impaired fetal growth, metabolic and electrolyte abnormalities, cardiovascular and CNS anomalies. In the present study $14.5 \%$ of the 
babies had hypoglycaemia. In the present study, $2.5 \%$ had congenital anomalies. According to Shefali et al., $1.4 \%$ babies had congenital anomalies, while according to Saxena et al., $10 \%$ babies had congenital anomalies. ${ }^{17}$

\section{Conclusion}

It is well known that GDM has adverse effect on mother and fetus. This study also emphasises the same. GDM mothers need management with multidisciplinary approach to ensure healthy mother and healthy newborn.

\section{Source of Funding}

None.

\section{Conflict of Interest}

None.

\section{References}

1. Obstet Gynecol. ACOG Practice Bulletin. Clinical management guidelines for obstetrician-gynecologists. Number 30, September 2001 (replaces Technical Bulletin Number 200, December 1994). Gestational diabetes. Obstet Gynecol. 2001;98(3):525-38.

2. Berger H, Crane J, Farine D, Armson A, Ronde SDL, Keenan-Lindsay $\mathrm{L}$, et al. Screening for gestational diabetes mellitus. J Obstet Gynaecol Can. 2002;24(11):894-912.

3. Diabetes Care. Gestational diabetes mellitus. Diabetes Care. 2003;26(1):103-5.

4. Brody SC, Harris R, Lohr K. Screening for gestational diabetes: a summary of the evidence for the U.S. Preventive Services Task Force. Obstet Gynecol. 2003;101(2):380-92.

5. Coustan DR. Making The Diagnosis of Gestational Diabetes Mellitus Clin Obstet Gynecol. 2000;43(1):99-105. 10i:10109710000308 200003000-00000

6. Wilkins-Haug L, Horton JA, Cruess DF, Frigoletto FD. Antepartum screening in the office-based practice: Findings from the Collaborative Ambulatory Research Network. Early Hum Dev. 1997;49(3):246-7. do1:10.1016/503/8-3/82(97)905/5-2.

7. Metzger BE. Summary and Recommendations of the Fourth International Workshop Conference on Gestational Diabetes Mellitus. Diabetes Care. 1998;21(2):161-7.

8. Swami SR, Mehetre R, Shivane V, Bandgar TR, Menon PS, Shah NS. Prevalence of carbohydrate intolerance of varying degrees in pregnant females in western India (Maharashtra) a hospital-based study. $J$ Indian Med Assoc. 2008;106:712-4.

9. Wahi P, Dogra V, Jandial K, Bhagat R, Gupta R, Gupta S. Prevalence of gestational diabetes mellitus (GDM) and its outcomes in Jammu region. J Assoc Physicians India. 2011;59:227-30.

10. Rajput R, Yadav Y, Nanda S, Rajput M. Prevalence of GDM In Haryana. Indian J Med Res. 2013;137:728-33.

11. Nanda S, Savvidou M, Syngelaki A, Akolekar R, Nicolaides KH. Prediction of gestational diabetes mellitus by maternal factors and biomarkers at 11 to 13 weeks. Prenat Diagn. 2011;31(2):135-41. do1:10.1002/pd.2630.

12. Saxena P, Nigam A, Tyagi S, Prakash A, Trivedi SS. Pregnancy outcome of women with gestational diabetes in a tertiary level hospital of North India. Indian J Community Med. 2011;36(2):120. 10:-10.4103/0070-(02) 8.84130.

13. Xiong X, Saunders LD, Wang FL, Demianczuk NN, et al Gestational diabetes mellitus: prevalence, risk factors, maternal and infant outcomes. Int J Gynecol Obstet. 2001;75(3):221-8. do1:10.1016/50020-7292(01)00496-9.

14. Toulis KA, Stagnaro-Green A, Negro R. Maternal Subclinical Hypothyroidsm and Gestational Diabetes Mellitus: A Meta-Analysis. Endocr Pract. 2014;20(7):703-14. बoi:10.4158/ep13440.ra

15. Kale SD, Yajnik CS, Kulkarni SR, Meenakumari K, Joglekar AA, Khorsand N, et al. High risk of diabetes and metabolic syndrome in Indian women with gestational diabetes mellitus. Diabetic Med. 2004;21(11):1257-8. do1:10.1111/].1464-5491.2004.01337.x.

16. Mahalakshmi MM. Clinical profile, outcomes, and progression to type 2 diabetes among Indian women with gestational diabetes mellitus seen at a diabetes center in south India. Indian J Endocrinol Metab. 2014;18(3):400-6.

17. Shefali AK. Pregnancy outcomes in pre-gestational and gestational diabetic women in comparison to non-diabetic women-a prospective study in asian indian mothers. J Assoc Physicians India. 2006;54:6138 .

\section{Author biography}

Rashmi K, Assistant Professor

Tejaswini D, Senior Resident

Radhika, Associate Professor

Anitha G S, Assistant Professor

Sukanya S, Senior Resident

Cite this article: Rashmi K, Tejaswini D, Radhika, Anitha G S, Sukanya S. A comparative study of efficacy of DIPSI and O'Sullivan's method of screening for GDM in a high risk tertiary referral hospital. Indian J Obstet Gynecol Res 2021;8(1):103-106. 